\title{
Didn't it mean a thing fit ain't got that swing? Swing Voters and Accountability Mechanism in the Japanese Lower House Election 2009'5
}

\section{Introduction}

The relationship between voter competence and democratic accountability is a controversial topic. In studies of American voters, there is a consensus that voters tend to be ill informed or ignorant about political matters (see Delli Carpini and Keeter, 1996). However, no consensus has been reached on the consequences and significance of this widespread political ignorance. Moreover, few studies have addressed voters' political knowledge and the various factors affecting their voting behavior in the Japanese political context.

In the theory of retrospective voting (Fiorina, 1981), voters are expected to evaluate the performance of the current administration and choose a party to vote for. If a voter is satisfied with the current administration, then he/she is expected to vote for it, and if he/she is not, his/her vote will go to the opposition party. Pessimistic views of voter competence criticize voters' capacity for evaluating governmental performances appropriately (Achen and Bartels, 2002; 2004; Healy and Malhotra, 2009). On the other hand, other scholars argue that having a low level of information does not necessarily have a negative influence on reasoned choice, because voters can learn and make inferences under some conditions ( $\mathrm{Lu}-$ pia, 1994; Popkin, 1994; Lupia and McCubbins, 1998; Lupia, McCubbins, and Popkin, 2000; Hutchings, 2003).

The current Japanese electoral politics provides an interesting case to consider the relationship between voter competence and democratic accountability. In

15 I would like to thank Gill Steel and Masayuki Jimichi for their helpful comments and Karol Zakowski and Toshimasa Moriwaki for providing the opportunity. This article is the one of the outputs from the Japanese Election Study 4 project (JES4), funded with Grants-in-Aid for Scientific Research by the Japan Society for the Promotion of Science since 2007-2011 as a "Specially Promoted Research Program" (19001001). The project's principal investigator was Hiroshi Hirano. The author appreciates all the project collaborators, Hiroshi Hirano, Ken'ichi Ikeda, and Yoshiaki Kobayashi. 
2009, Japanese politics experienced an epochal election: the Liberal Democratic Party (LDP) lost its majority in the Lower House (LH), and the Democratic Party Japan (DPJ) won power with two coalitional partners (the Social Democratic Party and the People's New Party). Behind the power shift, we can observe a national swing from the LDP to the DPJ at the time of the election.

By analyzing the aggregate data of the past three LH elections in Japan, Mori (2011) found that there was no great change at the level of votes for the third parties and concluded that the winners (the LDP in 2005, the DPJ in 2009) succeeded in winning floating votes. According to Mori's analysis, the LDP and the DPJ each had almost 20 million votes from their base voters; their landslide victories in the LH were accomplished by adding several million votes. This means that the shift of several million voters is critical to the democratic accountability mechanism in Japan. If these voters made a wise and competent choice, the current power shift in Japan should be celebrated. It is difficult, however, to imagine that all adults pay attention to politics as competent voters; it is easier to expect that several percentages of voters do so. Conversely, if the voters were myopic or unable to "manage the task of competent retrospection" (Achen and Bartels, 2004) we would not enjoy the accountability mechanism in Japanese electoral politics.

This paper assesses the relationship between the democratic accountability mechanism and voter competence. In particular, we focus on swing voters in 2009: i.e., those who voted for the DPJ in 2009 despite having voted for the LDP in 2005. Their voting behavior is of interest because it played an important role in ending the LDP rule, which began in 1955. By analyzing data on voter behavior and opinions, we seek to answer the question of whether the 2009 swing voters had sufficient political knowledge to make a wise and informed choice in the LH election, and what factors contributed to the swing vote.

This paper provides an important contribution to the study of voter competence and democratic accountability. As mentioned, research is lacking on the level of Japanese voters' political awareness and knowledge, and the potential consequences of voters' political ignorance have not yet been investigated. A case study of Japan's 2009 LH election will lend insights into recent voting behavior in Japan, paving the way for a discussion on the effects of voter competence on subsequent voter satisfaction and health of the nation.

Here we have some research questions. What kind of voting behavior did bring about the drastic power shift in 2009? To the question, our answer is the swing voting from the LDP to the DPJ. And, what kind of people did swung? Were they knowledgeable, or myopic? What kind of factors contributed to the swing voting? Finally, what kind of information environment helped the voters' swing?

To answer these questions, the remainder of this paper is organized as follows. Firstly, we confirm the aggregate level performance of the main parties in the past three LH's elections since 2003 to justify our focus on swing voting. Secondly, we check the level of political knowledge of swing voters versus stayers. 
Thirdly, we analyze different models of swing voting. Additionally, we will make sure about the political information environment among voters and enter the variables into our model of swing voting.

\section{National Swing in the Past Three Lower House Election}

Table 1 shows the voting results of the past three LH elections in Japan. For all the percentages, the denominator is the number of the enfranchised people, not voters. As Mori (2011) pointed out, there were major changes only for the LDP and the DPJ. In the 2005 election, as the table indicates, there was more than a 7 percent point increase in voter turnout. This increase benefited the LDP.

The LDP had kept a coalition government with Komeito since 1999. The two parties cooperated in national elections. For example, Komeito withdrew from races in many single-member districts (SMDs), and their supporters in these districts voted for the LDP. In the proportional representation (PR) part of the election, candidates from the LDP, who were supported by Komeito, encouraged their supporters to vote for Komeito. Although voting results in the SMDs are influenced by interparty cooperation and strategic entry and exit of the minor parties, in the PR portions, we see relatively stable space of the party competition. Then, this paper focuses on the PR votes. As mentioned above, in the 2005 election, the increase in voter turnout benefited the LDP: The vote share rose up 6 percentage points from 25.5 to 31.6. On the other hand, in the 2009 election, the vote share of the DPJ increased by 8 percentage points, and the LDP share decreased by 7 percentage points; however, the voter turnout increased just slightly (1.8 percentage points).

Table 1. Voting Results of the Past 3 Lower House Elections in Japan

\begin{tabular}{|c|c|c|c|c|c|c|c|c|}
\hline District & Year & $\begin{array}{c}\text { Numbers of } \\
\text { Enfranchized }\end{array}$ & $\begin{array}{c}\text { Voter } \\
\text { Turnout }\end{array}$ & LDP & DPJ & Komeito & Others & $\begin{array}{c}\text { Ineffective } \\
\text { Votes }\end{array}$ \\
\hline \multirow{3}{*}{ SMD } & 2003 & 102232944 & $59,9 \%$ & $25,5 \%$ & $21,3 \%$ & $0,9 \%$ & $10,5 \%$ & $1,7 \%$ \\
\cline { 2 - 9 } & 2005 & 102985213 & $67,5 \%$ & $31,6 \%$ & $24,1 \%$ & $1,0 \%$ & $9,5 \%$ & $1,4 \%$ \\
\cline { 2 - 9 } & 2009 & 103949442 & $69,3 \%$ & $26,3 \%$ & $32,2 \%$ & $0,8 \%$ & $8,1 \%$ & $2,0 \%$ \\
\hline \multirow{3}{*}{ PR } & 2003 & 102306684 & $59,8 \%$ & $20,2 \%$ & $21,6 \%$ & $8,5 \%$ & $7,4 \%$ & $2,0 \%$ \\
\cline { 2 - 9 } & 2005 & 103067966 & $67,5 \%$ & $25,1 \%$ & $20,4 \%$ & $8,7 \%$ & $11,5 \%$ & $1,7 \%$ \\
\cline { 2 - 9 } & 2009 & 103949442 & $69,3 \%$ & $18,1 \%$ & $28,7 \%$ & $7,7 \%$ & $10,7 \%$ & $4,0 \%$ \\
\hline
\end{tabular}

Source: Author own research query

Table 1 implies but does not definitively show the existence of voters who switched from the LDP in 2005 to the DPJ in 2009. We need to confirm the existence through the analysis of the survey data. We use the data from the Japanese Election Study 4, which covers the 2009 LH election at the second (pre-election) 
and third (post-election) waves. The JES4 is a panel survey project designed for conducting face-to-face interviews before and after elections. To examine voting behavior in the 2005 election, we use recall data. Respondents were asked two questions: whether they voted or not and for whom they voted. Table 2 is a crosstabulation of voting behavior at the PR districts in the 2005 and 2009 elections. This is a simple cross-tabulation table without any weights. As shown, the vote share of the LDP in 2005 was $48.4 \%$, which is inflated when we compare it with the real number $(25.1 \%)$ in Table 1 . On the other hand, the vote share of the DPJ in 2005 was not. However, in 2009, the vote share of the DPJ and LDP was also inflated in comparison to the real numbers in Table 1. The ratio of the abstention is discounted in each election: $7.1 \%$ in 2005 and 5.7\% in 2009. In survey studies, it is difficult to count the full number of absentees.

Table 2. Cross-tabulation of the Combination with Voting Behavior in 2005 and 2009

\begin{tabular}{|c|c|c|c|c|c|c|c|c|}
\hline & & \multicolumn{6}{|c|}{2009} & \\
\hline & LDP & DPJ & Komeito & $\begin{array}{c}\text { Other } \\
\text { Parties }\end{array}$ & Absteined & $\begin{array}{c}\text { DK/ NA/ } \\
\text { Blank } \\
\text { Ballot }\end{array}$ & Total \\
\hline 2005 & LDP & $22,8 \%$ & $17,7 \%$ & $2,3 \%$ & $3,0 \%$ & $1,9 \%$ & $0,6 \%$ & $48,4 \%$ \\
\cline { 2 - 9 } & DPJ & $0,9 \%$ & $17,0 \%$ & $0,3 \%$ & $2,6 \%$ & $0,3 \%$ & $0,3 \%$ & $21,3 \%$ \\
\cline { 2 - 9 } & Komeito & $0,4 \%$ & $1,1 \%$ & $2,9 \%$ & $0,3 \%$ & $0,2 \%$ & $0,1 \%$ & $4,9 \%$ \\
\cline { 2 - 9 } & Other Parties & $0,3 \%$ & $1,5 \%$ & $0,1 \%$ & $4,7 \%$ & $0,0 \%$ & $0,1 \%$ & $6,6 \%$ \\
\hline & Absteined & $0,9 \%$ & $3,0 \%$ & $0,1 \%$ & $0,8 \%$ & $2,2 \%$ & $0,2 \%$ & $7,1 \%$ \\
\hline & No Right & $0,4 \%$ & $0,5 \%$ & $0,1 \%$ & $0,1 \%$ & $0,3 \%$ & $0,0 \%$ & $1,4 \%$ \\
\cline { 2 - 9 } & $\begin{array}{c}\text { DK/ NA/ Forgot/ } \\
\text { Blank Ballot }\end{array}$ & $2,1 \%$ & $4,3 \%$ & $0,4 \%$ & $1,3 \%$ & $0,9 \%$ & $1,1 \%$ & $10,3 \%$ \\
\hline & Total & $27,8 \%$ & $45,1 \%$ & $6,3 \%$ & $12,8 \%$ & $5,7 \%$ & $2,3 \%$ & $100,0 \%$ \\
\hline & & & & & & & $\mathrm{n}=1580$ \\
\hline
\end{tabular}

Source: JES4 data (the 2nd and the 3rd wave)

In spite of the biases, Table 2 reveals that some voters switched from the LDP in 2005 to the DPJ in 2009. They are regarded as the swing voters in 2009. Koizumi voters seemed to have caused the DPJ victory, similar to swing voters in the U.S. who voted for Bush and then Obama (Lupia, 2010). Beginning in the next section, we compare swing voters with voters loyal to either the LDP or DPJ.

\section{Political Knowledge of Swing Voters and Stayers}

Generally, the amount of political information and knowledge that voters have is used as a proxy of political sophistication (Luskin, 1987; 2002). On the other hand, Lupia (2006) warned about elitist biases in conventional measurements of political 
knowledge and information for measuring voters' competence. Interestingly, in contrast to their colleagues in the U.S., Japanese political science researchers in academia have seldom produced studies that show voter ignorance and incompetence with positive evidence. However, increasing interest in populist persuasion by politicians such as Jun'ichiro Koizumi, an ex-prime minister, are vigilant to vulnerability of the Japanese mass to emotional mobilization tacit (Otake, 2003). To address the main concern of this paper, specifically, whether the swing voters in 2009 were wise enough to make a well-reasoned choice in the election, we begin by assessing the voters' level of political knowledge. The JES 4 survey prepared two sets of questions for asking about political knowledge. The first set of questions pertains to the second wave and the other to the third wave. The former asks respondents to "list as many ministries and governmental agencies as you can think of," and the latter contains three questions about political institutions and processes, five questions about parties' catchphrases, and three questions about political leaders. The maximum score is 14 points on the second wave battery and 11 points on the third.

Table 3 shows voters' level of political knowledge. The t-value was calculated by comparing the swing voters and two other kinds of stayers (i.e., the LDP and the DPJ stayers). There is a salient difference between the swing voters and the DPJ stayers in terms of their level of knowledge, in each battery. The DPJ stayers show the best performance in terms of statistical significance, but the swing voters show the worst on average and the lowest in standard deviation. However, at the 5\% significance level, there is no significant difference between the swing voters and the LDP stayers. This finding differs from our expectation. The leverage of the power transition in 2009 seems to be in the hands of less knowledgeable voters. However, the swing voters chose the knowledgeable side, at least in the electorate. Here, we reach the question of why such less knowledgeable voters decided to swing. What caused them to withdraw from the LDP? The next section addresses this question.

Table 3. Political Knowledge and Swing Voting

\begin{tabular}{|c|c|c|c|c|c|c|}
\hline & & $\mathrm{N}$ & Average & Standard Deviation & T-value & Significance Level \\
\hline \multirow{3}{*}{$\begin{array}{c}\text { 2nd Wave } \\
\text { Battery }\end{array}$} & All Respondents & 1858 & 3,69 & 3,24 & & \\
\cline { 2 - 8 } & Swing Voters & 279 & 3,51 & 3,09 & & \\
\cline { 2 - 8 } & LDP Stayers & 361 & 3,96 & 3,64 & 1,68 & 0,094 \\
\cline { 2 - 8 } & DPJ Stayers & 269 & 4,67 & 3,12 & $-4,36$ & 0,000 \\
\hline \multirow{3}{*}{$\begin{array}{c}\text { 3rd Wave } \\
\text { Battery }\end{array}$} & All Respondents & 1684 & 3,51 & 2,45 & & \\
\cline { 2 - 8 } & Swing Voters & 279 & 3,30 & 2,29 & & \\
\cline { 2 - 8 } & LDP Stayers & 361 & 3,46 & 2,41 & 0,84 & 0,398 \\
\cline { 2 - 7 } & DPJ Stayers & 269 & 4,53 & 2,40 & $-6,12$ & 0,000 \\
\hline
\end{tabular}

Source: Author own research query 


\section{Japanese Version of the Valence Model to Explain Swing Voting}

Japanese party politics have been approaching to the Westminster model since the introduction of the mixed electoral system with single-member districts and proportional representation to the LH election in 1996. As the adverse effect, Kobayashi (2008) points out that there is no great difference among the promises of the LDP and the DPJ at election time; moreover, such promises are dissociated from the voters' preference. This situation seems to fit with Clarke et al.'s (2009) valence politics model: a "large majority of voters agree about what the government should provide, but they disagree about which party is best able to achieve these consensual policy goals" (Clarke et al., 2009, p. 5).

Both economic voting and retrospective voting need competent opposition parties to switch a vote. In the LDP predominant party system from 1955 to 1993 under the SNTV electoral system, Japanese people did not have such alternatives. In those days, the economic recession resulted in more votes for the LDP (Yakushiji, 1987: 45-48). Yet, under the current tendency of bipartisan, the DPJ has been growing as a possible alternative office holder, as displayed in Figure 1. Thus, we have a motivation to create a Japanese version of the valence model to explain the swing voting in 2009.

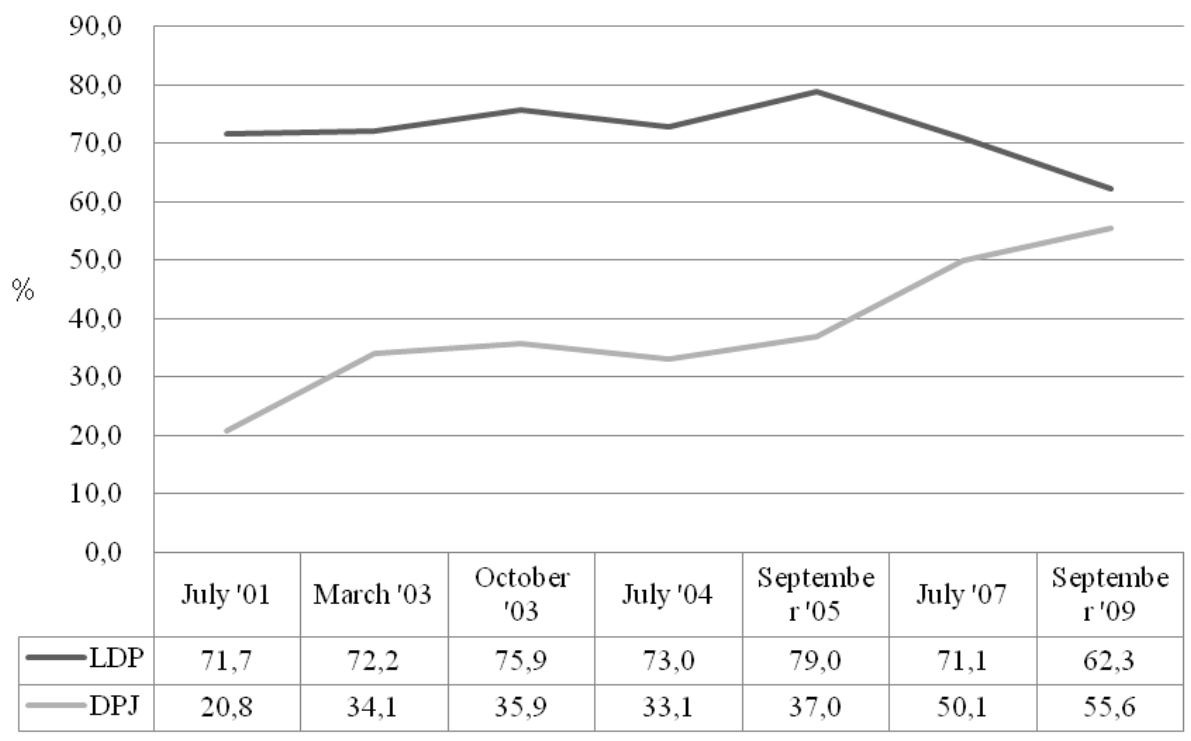

Figure 1. Evaluation to Governability Source: Author own research query

Using the similar reasoning, Iida (2010) analyzes and explains voting participation and votes for the DPJ with disappointment to the LDP and expectation to 
the DPJ as explanatory variables. We also focus on the evaluation and expectation of the incumbent government as well as the perception the DPJ's ability to govern. If a voter was satisfied with the performance of the incumbent cabinet, she or he had no reason to swing. If the governmental performance is poor but the expectations for the incumbent are still high, people may continue to support the ruling party. Then, we assume that voters try to compare each expectation for the incumbent and opposition. If expectations or evaluations of the opposition's ability to govern exceed those of the incumbent, we predict a swing to the opposition. On the other hand, we expect that a strong attachment to the party (e.g., party identification) will prevent voters from swinging, as the traditional theory says.

The model is estimated as a logit model. As for the variables for the evaluation of the incumbent cabinet and expectation of the incumbent cabinet, we expect a positive sign at both coefficients. At both variables, we predict that a greater number means worse for the incumbent then and will cause the swing. The coefficients of evaluation to the governability of the DPJ, interaction term of the expectation to the incumbent cabinet and the evaluation of thego vernability of the DPJ, relative likeability of the DPJ, and orientation to the DPJ dominance are also expected as positive as well.

The results of the model estimations are displayed in Table 4. We prepared three variants of the model. Model 1 is the simplest and unweighted. However, our sample is biased, especially at generational composition. As shown in Table 5, the younger generations of voters tend to be dropped out of our sample. Then, we created weights to modify the bias. Model 2 is the result of the weighted estimation. In Models 1 and 2 in Table 4, evaluation of the cabinet is not significant, but expectation is. This suggests that the feeling of hopelessness regarding the cabinet matter directly, not an evaluation of past performance. Then, we omitted it and estimated a new model as Model 3, which shows the most efficient performance with the Akaike Information Criteria (AIC) and the Baysian Information Criteria (BIC) ${ }^{16}$ among them.

Table 4. Logistic Estimation of Swing Voting in 2009

\begin{tabular}{|c|c|c|c|c|c|}
\hline & \multicolumn{2}{|c|}{ Model 1 (not weighted) } & \multicolumn{2}{|c|}{ Model 2 (weighted) } \\
\hline & coefficient & sig. & & coefficient & sig. \\
\hline Evaluation to the Cabinet Performance & $-0,153$ & 0,520 & $-0,221$ & 0,425 \\
\hline Expectation to the Cabinet & 0,368 & 0,038 & 0,435 & 0,014 \\
\hline Governability of the DPJ & 2,122 & 0,053 & & 2,286 & 0,047 \\
\hline $\begin{array}{c}\text { Interaction Term of "Expectation to the Cabi- } \\
\text { net" and "Governalibity of the DPJ" }\end{array}$ & $-0,327$ & 0,274 & $-0,378$ & 0,247 \\
\hline
\end{tabular}

16 We use STATA 12.1 for the estimation. In STATA, "fitstat" command enables us to compare the fit measures between two nested models. 
Table 4. (cont.)

\begin{tabular}{|c|c|c|c|c|c|}
\hline Relative Likeability to the DPJ & 0,007 & 0,000 & & 0,071 & 0,000 \\
\hline Orientation to the DPJ Dominance & 0,508 & 0,000 & & 0,653 & 0,000 \\
\hline Constant & $-3,114$ & 0,000 & & $-3,553$ & 0,000 \\
\hline -2LL & 377,882 & & & 326,919 & \\
\hline pseudo R-square & 0,505 & & & 0,520 & \\
\hline AIC & 0,707 & & & 0,615 & \\
\hline BIC & $-3077,608$ & & & $-3128,570$ & \\
\hline
\end{tabular}

Source: the Author own search query

Table 5. Weight Calculation from Generational Composition of Actual Voters and the Respondents

\begin{tabular}{|c|c|c|c|c|c|c|c|c|c|}
\hline & \multicolumn{2}{|c|}{ Basic Resident Registers } & \multicolumn{3}{c|}{ JES4 (3rd wave) } & \multicolumn{3}{c|}{ Weight (BRR/JES) } \\
\hline & Male & Female & Total & Male & Female & Total & Male & Female & Total \\
\hline $20 \mathrm{~s}$ & $7,1 \%$ & $6,8 \%$ & $13,9 \%$ & $2,1 \%$ & $2,9 \%$ & $4,9 \%$ & 3,417 & 2,382 & 2,818 \\
\hline $30 \mathrm{~s}$ & $9,2 \%$ & $8,8 \%$ & $17,9 \%$ & $5,2 \%$ & $5,8 \%$ & $11,0 \%$ & 1,754 & 1,507 & 1,624 \\
\hline $40 \mathrm{~s}$ & $7,9 \%$ & $7,7 \%$ & $15,6 \%$ & $6,4 \%$ & $8,0 \%$ & $14,4 \%$ & 1,233 & 0,959 & 1,081 \\
\hline $50 \mathrm{~s}$ & $8,3 \%$ & $8,3 \%$ & $16,6 \%$ & $8,4 \%$ & $11,4 \%$ & $19,8 \%$ & 0,983 & 0,728 & 0,836 \\
\hline $60 \mathrm{~s}$ & $8,1 \%$ & $8,6 \%$ & $16,7 \%$ & $12,6 \%$ & $13,7 \%$ & $26,3 \%$ & 0,639 & 0,628 & 0,634 \\
\hline $70 \mathrm{~s}$ & $5,4 \%$ & $6,7 \%$ & $12,1 \%$ & $8,6 \%$ & $9,3 \%$ & $17,8 \%$ & 0,631 & 0,720 & 0,677 \\
\hline over $80 \mathrm{~s}$ & $2,4 \%$ & $4,9 \%$ & $7,3 \%$ & $2,7 \%$ & $3,0 \%$ & $5,6 \%$ & 0,903 & 1,635 & 1,288 \\
\hline Total & $48,3 \%$ & $51,7 \%$ & $100,0 \%$ & $46,0 \%$ & $54,0 \%$ & $100,0 \%$ & 1,051 & 0,957 & 1,000 \\
\hline
\end{tabular}

Source: BRR is from the Ministry of Internal Affairs and Communication, Japan.

Even in Model 1, our predictions are almost supported, with some exceptions. The exceptions are the evaluation of cabinet performance and the interaction term of expectations to the cabinet and the governability perception of the DPJ. Neither is statistically significant. However, in Model 3, after dropping the evaluation of the cabinet performance, all variables become significant and the sign coefficients support our prediction, except for the interaction term. As we hypothesized, the variables of lower expectation to the cabinet, governability perception of the DPJ, relative likeability of the DPJ, and the orientation to the DPJ dominance tend to contribute to swing voting in 2009. However,the interaction term of expectation to the cabinet and the governability perception of the DPJ has a discounting effect.

Table 4 displays that our models demonstrate good performances to predict swing voting in 2009. Next we proceed to focus on the relative contribution of each variable. In a logit model, the odds ratio is used as an index for comparing 
the degree of relative impacts among explanatory variables to explain the variance of the independent variable (Long and Freese, 2003, 145-9). It is calculated as an exponential of a regression coefficient. In our model, the governability perception of the DPJ shows the highest value at the odds ratio. Next, we will focus on this variable.

Figure 2 illustrates the comparison of the cognition about the governability of the DPJ with the LDP stayers and swing voters. The share of people who regard the DPJ as a party that is able to govern is opposite on the two sides. Seventy percent of LDP stayers do not recognize the DPJ as capable of managing the government. On the other hand, $70 \%$ of the swing voters do. These analyzes imply that the governability of the DPJ could be a critical shortcut for a decision to swing.

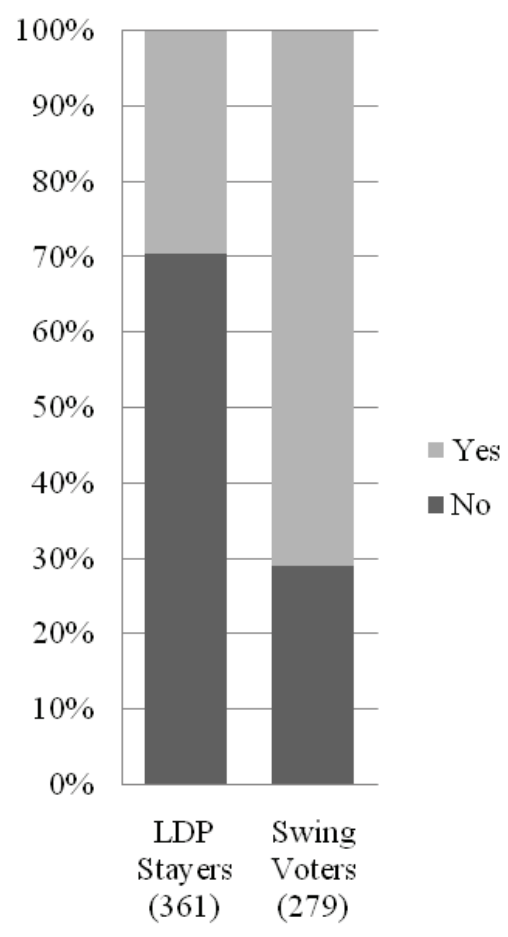

Figure 2. Governability of the DPJ and Swing Voters

Source: the Author own search query.

These results show that our valence model explains the swing voting in 2009 very well. The reasons for the swing are disappointment with the incumbent cabinet, recognition of the opposition's ability to govern and hope for a shift in the balance of political power. These represent a quite natural reasoning. Even so, in Japan, the change in voting behavior meant a breakdown of the party that had dominated since 1955 . 
Is this kind of reasoning blind retrospection? As we found, swing voters are less knowledgeable than DPJ stayers. Now we consider how they reached to the decision to swing. Is it blind retrospection or low information rationality? With this question in mind, we examine their information strategy in the next section.

\section{Information Environment of Swing Voters}

In this section, we compare 2009 swing voters with LDP stayers from the viewpoint of information strategy and environment. The JES4 data has a battery to ask the respondents about helpful information sources that they used in making their voting decision. Multiple answers are allowed. We prepared 14 possible information sources like television and radio programs. The results of cross-tabulation analysis with a chi-square test do not show a salient difference between the swing voters and LDP stayers. Although we have checked the media usage of the two types of voters, significant differences could not be detected. Ikeda et al. (2005) indicates that stability in party identification was predicted by the interpersonal political environment (IPE) with data from Japan and New Zealand. The IPE refers to political affiliations and preferences of others in a person's social network. To evaluate the implication of this finding for our study, we check the IPE of the 2009 swing voters.

The second wave survey of the JES4 asks the respondents about their political discussion partners (at most 4 persons). Discussion partners are defined as any person (e.g., family members, co-workers, friends) that the respondent discussed politics with prior to casting his or her vote in the 2009 election. The survey asked which party each partner would vote for and whether the partner supported the Aso Cabinet.

Using this information, we compared the swing voters with the LDP stayers. As for the number of discussion partners, no difference was found among them. Table 6 shows a comparison with the swing voters and the LDP stayers in terms of three perceptions: the predicted numbers of the discussion partners who will vote for the LDP or the DPJ and support the incumbent cabinet. When the respondents have no partners who will vote for the LDP, $58 \%$ of them swing. However, when there is even one person who will vote for the LDP, the shares of the swing voters decrease dramatically. When the respondents have no discussion partners planning to vote for the DPJ, $65 \%$ of them vote again for the LDP. However, when they have even one discussion partner planning to vote for the DPJ, the shares of the swing vote increases drastically. Additionally, when there is no person to support the cabinet, each share of swing voters and the LDP stayers constitute almost 50\%. However, in the case where the respondents have even one person to support the cabinet, the share of swing voters 
declines and that of LDP stayers rises. Thus, we observe a strong correlation between the IPE and swing voting.

Table 6. Swing Voting and Discussion Partners

\begin{tabular}{|c|c|c|c|c|c|}
\hline & \multicolumn{5}{|c|}{ Predicted Numbers of the Discussion Partners who will vote for the LDP } \\
\hline & 0 & 1 & 2 & 3 & 4 \\
\hline Swing Voters & $58 \%$ & $25 \%$ & $7 \%$ & $22 \%$ & $13 \%$ \\
\hline LDP Stayers & $42 \%$ & $75 \%$ & $93 \%$ & $78 \%$ & $87 \%$ \\
\hline $\mathrm{N}$ & 395 & 162 & 45 & 23 & 15 \\
\hline & \multicolumn{5}{|c|}{ Predicted Numbers of the Discussion Partners who will vote for the DPJ } \\
\hline & 0 & 1 & 2 & 3 & 4 \\
\hline Swing Voters & $35 \%$ & $68 \%$ & $82 \%$ & $80 \%$ & $75 \%$ \\
\hline LDP Stayers & $65 \%$ & $32 \%$ & $18 \%$ & $20 \%$ & $25 \%$ \\
\hline $\mathrm{N}$ & 487 & 111 & 28 & 10 & 4 \\
\hline & \multicolumn{5}{|c|}{ Predicted Numbers of the Discussion Partners who support the Cabinet } \\
\hline & 0 & 1 & 2 & 3 & 4 \\
\hline Swing Voters & $51 \%$ & $24 \%$ & $15 \%$ & $12 \%$ & $11 \%$ \\
\hline LDP Stayers & $49 \%$ & $76 \%$ & $85 \%$ & $88 \%$ & $89 \%$ \\
\hline $\mathrm{N}$ & 491 & 96 & 27 & 17 & 9 \\
\hline
\end{tabular}

Source: the Author own research query.

Many voters may not so be politicized and, therefore, may not recognize the voting intention of their discussion partners. We hope to confirm it. Table 7 shows the cross-tabulation of each predicted number of political discussion partners who will vote for the LDP and the DPJ. This table makes clear that $50 \%$ of the people, including those without any partners for political discussion, do not recognize their discussion partner's voting direction. Moreover, we find that only $4.2 \%$ (shaded area of Table 7) of people have plural discussion partners who intend to vote for different party. 
Table 7. Cross-tabulation of the Predicted Numbers of the Discussion Partners to vote for the LDP and the DPJ

\begin{tabular}{|c|c|c|c|c|c|c|c|}
\hline & \multicolumn{6}{|c|}{$\begin{array}{c}\text { Predicted Numbers of the Discussion Partners who will } \\
\text { vote for the LDP }\end{array}$} & \\
\hline & & 0 & 1 & 2 & 3 & 4 & Total \\
\hline $\begin{array}{c}\text { Predicted Numbers } \\
\text { of the Discussion } \\
\text { Partners who will } \\
\text { vote for the DPJ }\end{array}$ & 0 & $50,8 \%$ & $13,8 \%$ & $3,8 \%$ & $1,6 \%$ & $1,3 \%$ & $71,3 \%$ \\
\cline { 2 - 9 } & 2 & $17,0 \%$ & $1,7 \%$ & $1,0 \%$ & $0,1 \%$ & $0,0 \%$ & $19,8 \%$ \\
\cline { 2 - 9 } & 3 & $1,8 \%$ & $0,4 \%$ & $0,0 \%$ & $0,0 \%$ & $0,0 \%$ & $2,1 \%$ \\
\cline { 2 - 9 } & 4 & $0,8 \%$ & $0,0 \%$ & $0,0 \%$ & $0,0 \%$ & $0,0 \%$ & $0,8 \%$ \\
\hline & Total & $75,3 \%$ & $16,9 \%$ & $4,8 \%$ & $1,7 \%$ & $1,3 \%$ & $100,0 \%$ \\
\hline & & & & & & & $\mathrm{n}=1684$ \\
\hline
\end{tabular}

Source: the Author own research query.

Here, we proceed to include these IPE variables into the multivariate estimation. We created three dummy variables to indicate the feature of discussion partners for the respondents. The first displays whether there is at least one discussion partner who supports the cabinet. The second shows whether there is at least one partner to vote for the DPJ, and the third shows whether there is at least one partner to vote for the LDP. By entering these three dummy variables into Model 3 in Table 4, we produce Model 4 in Table 8. This does not entail any major changes. Among the newly entered dummy variables, only the LDP vote prediction among discussion partners is statistically significant. This means that the existence of the LDP voter among respondents' discussion partners tends to keep them from swing voting, but DPJ voters or cabinet supporters do not have such an effect. This is a very interesting finding. What about the fitness of the model? Model 3 and 4 are nested and are able to be compared at the performance using the BIC measure. The comparison shows us that Model 3 is superior to Model 4, because the difference of the BIC between them is 6.425, which strongly supports Model 3. Model 4 includes two insignificant variables, cabinet supporter among discussion partners and DPJ vote prediction among discussion partners. Then, we dropped both variables and tried a new estimation as Model 5 in Table 8. The values of coefficients and the sign are not changed, but the value of the BIC is improved. When we compare Model 5 and Model 3, we observe a difference of 3.662 in the BIC, which provides positive support for Model 5. 
Table 8. Logistic Estimation with Discussion Partners' Effect

\begin{tabular}{|c|c|c|c|c|c|c|}
\hline & \multicolumn{2}{|c|}{ Model 4} & \multicolumn{2}{|c|}{ Model 5} & \multicolumn{2}{|c|}{ Model 6} \\
\hline & coefficient & sig. & coefficient & sig. & coefficient & sig. \\
\hline Expectation to the Cabinet & 0,388 & 0,027 & 0,347 & 0,050 & 0,338 & 0,059 \\
\hline Governability of the DPJ & 2,811 & 0,002 & 2,936 & 0,002 & 2,919 & 0,002 \\
\hline $\begin{array}{l}\text { Interaction Term of "Ex- } \\
\text { pectation to the Cabinet" } \\
\text { and "Governalibity of } \\
\text { the DPJ" }\end{array}$ & $-0,549$ & 0,024 & $-0,570$ & 0,020 & $-0,556$ & 0,026 \\
\hline $\begin{array}{c}\text { Relative Likeability to } \\
\text { the DPJ }\end{array}$ & 0,067 & 0,000 & 0,066 & 0,000 & 0,067 & 0,000 \\
\hline $\begin{array}{c}\text { Orientation to the DPJ } \\
\text { Dominance }\end{array}$ & 0,624 & 0,000 & 0,643 & 0,000 & 0,624 & 0,000 \\
\hline $\begin{array}{l}\text { Cabinet Supporter among } \\
\text { Discussion Partners }\end{array}$ & 0,603 & 0,139 & & & & \\
\hline $\begin{array}{l}\text { DPJ Vote Prediction } \\
\text { among Discussion } \\
\text { Partners }\end{array}$ & 0,298 & 0,358 & & & & \\
\hline $\begin{array}{l}\text { LDP Vote Prediction } \\
\text { among Discussion } \\
\text { Partners }\end{array}$ & $-1,110$ & 0,002 & $-0,946$ & 0,002 & & \\
\hline $\begin{array}{l}\text { Predicted Number of LDP } \\
\text { votes }\end{array}$ & & & & & $-0,583$ & 0,003 \\
\hline Constant & $-3,812$ & 0,000 & $-3,617$ & 0,000 & $-3,591$ & 0,000 \\
\hline$-2 \mathrm{LL}$ & 315,144 & & 317,691 & & 317,358 & \\
\hline pseudo R-square & 0,538 & & 0,534 & & 0,534 & \\
\hline AIC & 0,601 & & 0,599 & & 0,598 & \\
\hline $\mathrm{BIC}$ & $-3127,711$ & & $-3137,798$ & & $-3138,131$ & \\
\hline & & & & & & $\mathrm{n}=554$ \\
\hline
\end{tabular}

Source: the Author own research query

As the final analysis, instead of the dummy variable, we enter the real number that the respondents predicted among their discussion partners in Model 6. The estimation result is almost same, but the value of the BIC is slightly improved from Model 5. Here, we have confirmed the effectiveness of our variables and hypotheses. Lower expectations of the incumbent cabinet and the perception of governability of the DPJ contributed to the 2009 swing vote, although the interaction term of both variables discounts the effects of each variable. Relative likability of the DPJ compared with the LDP and orientation to the DPJ dominance also had positive effects on swing voting. As one of the IPE variables, only the existence of probable LDP voters among a respondent's circle of discussion partners tended to prevent them from swinging. 


\section{Conclusion}

This paper investigates the democratic accountability mechanism. It is essential to democracy that voters are able to create a shift in national political power through an election when they are dissatisfied with the performance of the current government. The question is who can trigger such a shift in Japan's 2009 LH election: knowledgeable or uninformed voters? Our result shows that swing voters are neither outstandingly knowledgeable nor ideal citizens. The study's findings on political knowledge indicate that they are very ordinary people. On the other hand, the DPJ stayers in the study were more knowledgeable than average voters, and the LDP stayers and swing voters followed the DPJ stayers. Given the unpopularity of the cabinet at the time of the election, some people who regarded the DPJ as more capable of managing government swung from the LDP to the DPJ. Thus, swing voters in 2009 made the same voting choice as the DPJ stayers, who were the most politically knowledgeable. Should their decision be criticized, or did it make sense in terms of political knowledgeability?

The DPJ cabinet is currently experiencing a low approval rate $(21.3 \%$ in July 2012 , as reported by Jiji press). Many swing voters may regret their own choice in the 2009 election. Yet, did Japanese voters make a mistake in the 2009 election? Was it blind retrospection? At least, it is true that the government led by the LDP could not satisfy the majority of voters or even a plurality at the time of the election. Therefore, the swing voters chose the opposition, and the LDP government was replaced. This is a healthy mechanism of democratic accountability. Moreover, the DPJ stayers were more knowledgeable than the LDP stayers and average voters. The swing voters stood on a more knowledgeable side. If it should be criticized, perhaps democracy should be as well.

In terms of media usage, our analysis did not find significant differences among stayers for each party and swing voters. However, among the LDP stayers, the existence of probable LDP voters among the respondents' discussion partners tends to prevent them from swinging, as our multivariate analyses shows. On the other hand, the existence of probable DPJ voters does not have a significant effect on the swing vote. These findings may imply that LDP voters face stronger peer-pressure from other LDP voters to vote again for the LDP than other types of voters. This presumption is consistent with the fact that the LDP was a ruling party for more than 50 years and has organized an indigenous social network (Flanagan, 1991).

An important limitation of this study should be noted, namely, the reliance on recall data. We asked respondents about their voting behavior four years ago. Thus, the accuracy of the data may have been compromised by respondents' unintentional memory lapses or conscious misrepresentations of the past (Powers et al., 1978). We must also consider potential biases accompanying the use of longitudinal survey data (Weisberg, 2005). Future research should expand on the findings 
here by clarifying the effect of peer-pressure on LDP voters and identifying other potential factors of swing voting in Japan. Comparison of voting in the Japanese context and voting in other Asian or world contexts will also shed further light on the broader issue of democratic accountability and voter competence.

\section{References}

Achen, Christopher H., and Larry M. Bartels. (2002). "Blind Retrospection: Electoral Responses to Drought, Flu, and Shark Attacks." Prepared for the Annual Meeting of the American Political Science Association, Boston, USA.

Aida, Masahiko., and Ken'ichi Ikeda. (2005). "Non-response and Unequal Sampling Probability in Longitudinal Election Survey." Review of Electoral Studies (5): 5-21.

Clarke, Harold D., David Sanders, Marianne C. Stewart., and Paul F. Whiteley. (2009). Performance Politics and the British Voter. Cambridge: Cambridge University Press.

Fiorina, Morris P. (1981). Retrospective Voting in American National Elections. Yale University Press.

Hutchings, Vincent. 2003. Public Opinion and Democratic Accountability: How Citizens Learn about Politics. Princeton University Press.

Iida, Takeshi. (2010). "Disappointment, Hope, and Voting Behavior in the 2009 Japanese General Election.” Prepared for the Annual Meeting of Japanese Association of Electoral Studies, Tokyo, Japan.

Ikeda, Ken'ichi. (2002). "Social Capital and Social Communication in Japan: Analysis on Survey Data on Political Participation Before and During the General Election 2000." Japanese Journal of Electoral Studies (17):5-18.

Ikeda, Ken'ichi. (2004). "Japanese House of Councilors Election in 2001 and "Koizumi Prime Minister Effect.” Japanese Journal of Electoral Studies (19):29-50.

Ikeda, Ken'ichi. (2007). Political Reality and Social Psychology: The Dynamics of the Koizumi Years. Bokutakusha, Tokyo, Japan.

Ikeda, Ken'ichi, James H. Liu, Masahiko Aida., and Marc Wilson. (2005). "Dynamics of Interpersonal Political Environment and Party Identification: Longitudinal Studies of Voting in Japan and New Zealand." Political Psychology (26;4): 517-542.

Imai, Ryosuke. (2008b). "The "Conditioning" Effect of Political Knowledge on Voting Behavior." The Annuals of Japanese Political Science Association (2008- I):283-305.

Kobayashi, Yoshiaki. (2008). Is Democracy Working in Japan After the Political Reform . Bokutakusha, Tokyo, Japan.

Long, J. Scott, and Jeremy Freese. (2003). Regression Models for Categorical Dependent Variables Using Stata, Revised Edition. Stata Press.

Lupia, Arthur. (1994). "Shortcuts versus Encyclopedias: Information and Voting Behavior in California Insurance Reform Elections." American Political Science Review (88):63-76.

Lupia, Arthur. (2006). "How Elitism Undermines the Study of Voter Competence." Critical Review (18): 217-232.

Lupia, Arthur. (2010). “Did Bush Voters Cause Obama's Victory?” PS: Political Science \& Politics (43): 239-241.

Lupia, Arthur., and Mathew D. McCubbins. (1998). The Democratic Dilemma: Can Citizens Learn What They Need to Know? Cambridge University Press.

Lupia, Arthur, Mathew D. McCubbins., and Samuel L. Popkin (eds.). (2000). Elements of Reason: Cognition, Choice, and the Bounds of Rationality. Cambridge, Cambridge University Press. 
Luskin, Robert C. (1987). "Measureing Political Sophistication." American Journal of Political Science (31): 856-899.

Luskin, Robert C. (2002). "From Denial to Extenuation (and Finally Beyond): Political Sophitication and Citizen Performance." In James H. Kuklinski (ed.) Thinking About Political Psychology. Cambridge University Press: 281-305.

Mori, Hiroki. (2006). "The 2005 General Election and the State of the Party System in Japan." Leviathan (39): 70-99.

Mori, Hiroki. (2011). "2009 nen Sou-senkyo no Tokuhyou Bunseki. (Analysis of Party Votes in the 2009 Lower House Election)." Doshisha Hougaku (347): 595-629.

Otake, Hideo. (2003). Nihon-gata Populism (Japanese Way of Populism). Tokyo: Chuo- Koron- sha.

Popkin, Samuel L. (1994). The Reasoning Voter: Communication and Persuasion in Presidential Campaigns, second edition. Chicago: The University of Chicago Press.

Powers, Edward A., Willis J. Goudy., and Pat M. Keith. (1978). "Congruence Between Panel and Recall Data in Longitudinal Research.” Public Opinion Quarterly (42;3): 380-389.

Weisberg, Herbert F. (2005). The Total Survey Error Approach: A Guide to the New Science of Survey Research. Chicago: The University of Chicago Press. 